This item was submitted to Loughborough's Research Repository by the author.

Items in Figshare are protected by copyright, with all rights reserved, unless otherwise indicated.

\title{
Governance and knowledge management and transfer: the case of the Lillehammer 2016 Winter Youth Olympic Games
}

PLEASE CITE THE PUBLISHED VERSION

https://doi.org/10.1504/IJSMM.2017.10008118

\section{PUBLISHER}

(C) Inderscience

\section{VERSION}

AM (Accepted Manuscript)

\section{PUBLISHER STATEMENT}

This work is made available according to the conditions of the Creative Commons Attribution-NonCommercialNoDerivatives 4.0 International (CC BY-NC-ND 4.0) licence. Full details of this licence are available at: https://creativecommons.org/licenses/by-nc-nd/4.0/

\section{LICENCE}

CC BY-NC-ND 4.0

\section{REPOSITORY RECORD}

Parent, Milena M., Elsa Kristiansen, and Barrie Houlihan. 2019. "Governance and Knowledge Management and Transfer: The Case of the Lillehammer 2016 Winter Youth Olympic Games”. figshare. https://hdl.handle.net/2134/34345. 


\title{
Governance and Knowledge Management and Transfer: The Case of the Lillehammer 2016 Winter Youth Olympic Games
}

\author{
Milena M. Parent \\ University of Ottawa and Norwegian School of Sport Sciences \\ 125 University Private, Ottawa, Ontario, K1N 6N5, Canada; \\ milena.parent@uottawa.ca
}

\section{Elsa Kristiansen}

University College of Southeast Norway and Norwegian School of Sport Sciences

Postboks 4, 3199 Borre, Norway; elsa.kristiansen@hbv.no

\section{Barrie Houlihan}

Loughborough University and Norwegian School of Sport Sciences

School of Sport and Exercise Sciences, Loughborough University, Loughborough, LE113TU, UK; b.m.j.houlihan@lboro.ac.uk

\begin{abstract}
This paper examines the relationship between knowledge management/transfer processes and (good) governance practices in sports events. The research was undertaken at the Lillehammer 2016 Winter Youth Olympic Games, with data collected through interviews and document analysis. Findings include a) the significance of horizontal as well as hierarchical accountability; b) different event logics for the event rights holder-organizing committee relationship; c) the importance of culture as well as structure in relation to governance; and d) the significance of tacit knowledge, person-toperson informal knowledge transmission, and knowledge transfer timing.
\end{abstract}

Keywords: Governance; Knowledge Management; Knowledge Transfer; Accountability; Youth Olympic Games; Norway; International Olympic Committee; Sport Event Management; Culture

Reference to this paper should be made as follows: Author. (xxxx) 'Title', Int.

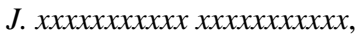

\section{Introduction}

The International Olympic Committee (IOC) and FIFA (Fédération Internationale de Football Association) are but two international sport organizations and sport event rights 
Parent et al.

holders dealing with serious issues of governance, accountability and the management of knowledge. These issues have already stimulated research within the sport management literature (e.g., Chappelet and Kübler-Mabbott, 2008; Ferkins and Shilbury, 2015a; 2015b; Girginov, 2012; Parent, 2016a; Shilbury and Ferkins, 2015). Governance, accountability, and knowledge management in the context of sport and sports events can be examined at a micro or intra-organizational level (e.g., board behaviour, power, and relationship with stakeholders and staff) or a macro or inter-organizational level, that is, examining 'the overall system by which all the actors associated with delivering [the sport or sport event] are controlled, coordinated and held accountable' (Hoye, In press: 2). Whichever level is the primary concern, it is clear governance and the related concerns are significant issues within sport (event) management.

Regarding knowledge management and transfer, it is an increasingly pressing concern for event rights holders and their partners. Knowledge management/transfer can even be considered a legacy of an event, as in the case of the Toronto 2015 Pan and Para-pan American Games, which developed a knowledge management/transfer plan for use by subsequent organising committees (see Schenk et al., 2015). Here, knowledge management/transfer refers to the various aspects associated with the knowledge management/transfer process: knowledge identification, acquisition, creation, tailoring storage, application and transfer (Schenk et al., 2015).

While knowledge management/transfer has been defined and its general process understood within the context of major sports events (e.g., Halbwirth and Toohey, 2001; Parent et al., 2014b), this has been done in relative isolation from other organizational processes (e.g., governance, accountability or human resource management), despite the usual acknowledgment by researchers that the sport event context is complex (cf. Schenk et al., 2015). A similar criticism can also be made of discussions of governance structures (especially when the focus is on the requirements for 'good governance'), where there is often an assumption that good governance is an end in itself rather than a contribution to the fulfilment of organisational objectives (Grindle, 2016).

We believe sport event management research must move beyond a focus on singleconcepts towards an understanding of concepts in relation to each other. As such, the purpose of this paper is to examine the relationship between knowledge management/transfer processes, accountability and good governance practices in sports events. The empirical focus for our research is the Youth Olympic Games (YOG), a relatively new event - the first edition being Singapore 2010 - and therefore one which has not been studied in great depth (cf. Hanstad et al., 2013; 2014). To our knowledge, no research has examined the interrelationship between governance and knowledge management/transfer processes in relation to the YOG. As such, this provides an opportunity not only to compare and contrast our existing understanding of sport event knowledge management/transfer processes in this new context, but also to examine sport event governance in a new setting and to examine the interrelationship between governance and knowledge management/transfer processes.

Our specific research questions are: 1) what is the relationship between good governance principles and the knowledge management/transfer process; and 2) to what extent does knowledge management/transfer in the YOG compare with that of the Olympic Games process?

We first provide an overview of the relevant literature before describing our methodology and context. We then present and discuss our results, concluding with implications and future directions. 
Governance and knowledge management and transfer: The case of the Lillehammer 2016 Winter Youth Olympic Games

\section{Examining (good) governance and knowledge management}

\subsection{Governance}

Though the concept of governance is a central concern in contemporary debates on public policy and organisational decision-making, an agreed definition remains elusive. Van Kersbergen and van Waarden (2004) identified nine different definitions, while Rhodes (1997, p. 653) questioned whether the concept had 'too many meanings to be useful.' These definitional challenges notwithstanding there is broad agreement that decisionmaking in complex areas, such as major sports events organisation, has shifted from a traditional pattern of hierarchic self-government towards a pattern of horizontal networked governance, in which the management of a complex array of stakeholders is a key requirement.

Although research into sport event governance is in its infancy, there are a number of key studies which form a sound basis of our theoretical framework. First, intraorganizational governance aspects have been examined, mainly through an organization theory lens. To wit, Theodoraki (2007) noted organising committees of Olympic Games (OCOGs) are usually incorporated as not-for-profit organizations, associations or foundations, though some, as in the case of Athens 2004, are state-owned. She added OCOGs are hybrid structures, combining Mintzberg's (1979) divisionalised and missionary forms, and move from work processes standardisation during the planning period to outputs and skills standardisation during Games-time.

In a similar vein, Parent (2008) argued major sport event organising committees move through three operational modes: 1) planning, which includes the bid and transition phases, as well as the writing of the business plan, operational plan and divisional plans/work packages; 2) implementation, which starts about halfway through the organising committee's life and which includes the preparation of the venue plans plus the venuisation (movement/transition) to the venues and the actual Games-time; and 3) wrap-up, which starts immediately after the closing ceremonies end, and which includes decommissioning the venues, writing the final reports, dealing with the legacies, and closing the books.

Second, part of governing the event includes managing the event's stakeholders, that is, inter-organizational event governance. Major sport event stakeholders include the organising committee's staff and volunteers, the community (schools, residents, activists, local business and tourism organisations, etc.), national and international sponsors, the media (print, radio, photography, broadcasting and social media), the delegations (athletes, coaches, support staff, etc.), the sport organisations (the rights holder and the local to international sport federations), and the host governments (Parent, 2008). Of note, the host governments and event rights holder usually form the key partners of an event.

At a broader, systemic level, Chappelet and Kübler-Mabbott (2008) examined the IOC and its governance of the Olympic Movement. Beyond describing key actors (the IOC, the national Olympic committees, OCOGs, international sport federations, governments and regulators), they argued the IOC is involved in five levels of governance: management, corporate governance, governance management, harmonisation, and meta-governance. To govern at each level, the authors argued 
Parent et al.

transparency, democracy, accountability, autonomy, and social responsibility ought to be guiding principles. Chappelet and Kübler-Mabbott's work is illustrative of the second major conceptualisation of governance that is both normative and prescriptive and concerns the aspiration to achieve 'good governance.'

The principles identified by Chappelet and Kübler-Mabbott support Parent’s (2016b) findings that democratic governance principles - specifically, performance, accountability, transparency, and stakeholder participation - comprise a useful framework for examining the governance of major sports events and their associated stakeholders. Here, performance refers to efficiency, effectiveness and economy (Bevir, 2010; Callahan, 2007; Parent, 2016b), while accountability, within a sport event context, includes internal (hierarchical) accountability and external (stakeholder) accountability (Parent, 2016b). In turn, transparency requirements seem stronger within an organisation than outside it, while stakeholder (external) participation differs from internal participation by organisational members based on responsibilities (Parent, 2016b). Finally, Parent argued the physical, mental and emotional engagement of stakeholders towards an event should be part of the event governance process.

The increasing interest in contemporary governance processes requires a reconceptualisation of the concept of accountability that is rightly seen as a fundamental attribute of good governance. Of particular relevance to understanding the governance of major event organisations is the acknowledgement that traditional upwards, straight-line accountability (for example, to the IOC as rights holder and government as funder and risk underwriter) often operates alongside neo-liberal 'downward' accountability to the market (to consumers) and 'extended accountability' within which 'traditional accountability is only part of a cluster of mechanisms through which public bodies [and semi-public bodies such as Youth Olympic organising committees] are in fact held to account' (Scott, 2000, p. 245). However, accountability, much like the concept of governance, lacks a precise definition. Stewart (1994: 77) views accountability as involving 'both giving an account and ... being held to account': having an obligation to explain and being liable for decisions. For others, accountability is primarily a control mechanism (Romzek 1996) or a means of preventing the abuse of power (Thomas 1998). Mapping accountability entails identifying who is accountable, for what, how, to whom and with what outcome. These questions can be grouped into three themes: first, exploring the balance between the provision of an explanation, the exercise of control, and the establishment of liability (Newman, 2004); second, examining attitudes towards the accountability relationship and the extent to which it is seen as a legitimate obligation by the organisation being held to account (O’Loughlin, 1990; de Leon, 2003); and third, the mechanisms through which the relationship is operationalised.

As previously noted, there has been limited research regarding YOG-specific governance and accountability processes, with recent studies focusing on topics such as the idea and value of the YOG (e.g., Digel, 2008; Hanstad et al., 2014; Loland, 2014; Parry, 2012; Wong, 2011), young athletes' experiences (e.g., Krieger, 2013; Kristiansen, 2013; Parent et al., 2014a), economic impact (Thöni and Philippovich, 2008; Preuss, Siller, Schütte, Zehrer, Stickdorn, 2010; Schnitzer, Bodner, Scheiber, Thöni and Kopp, 2015), and customer satisfaction (Preuss et al, 2010; Schnitzer and Stickdorn, 2012). An exception is Parent et al. (2015), who examined the stakeholder network of the first Winter YOG in Innsbruck, thus drawing attention to inter-organisational governance aspects. These authors found three central stakeholders in the YOG's stakeholder 
Governance and knowledge management and transfer: The case of the Lillehammer 2016 Winter Youth Olympic Games

network: the event rights holder (the IOC), the press and broadcast media, and the athletes' parents.

As such, there is a need to consider the intra-organisational governance of the YOG along with inter-organisational (stakeholder) governance, and to understand the key aspects related to the governance of the YOG more generally.

\subsection{Knowledge Management and Transfer}

Knowledge is more than information (know-what), it is also know-how and constitutes one of the most valuable organisational assets (Jasimuddin, 2012). Knowledge may be explicit (written, codified) or tacit (inarticulate, internal to a person, more experiencebased), the latter being harder to manage and transfer (cf. Parent et al., 2014b; Polanyi, 1966; Winter, 1987; Zander and Kogut, 1995).

From a review of 160 knowledge management frameworks, Heisig (2009) argued for six main knowledge-related activities (see also Parent et al., 2014b):

- Acquisition: collecting/harnessing knowledge needed to undertake a certain task;

- Application: using knowledge needed to perform a given task;

- Creation: producing new knowledge;

- Identification: ascertaining the knowledge required to undertake a given task;

- $\quad$ Storage: retaining, protecting and maintaining knowledge useful for a given task for subsequent use; and

- $\quad$ Transfer: knowledge delivery from sender to receiver.

Utilising Heisig’s review, Parent et al. (2014b) and Schenk et al. (2015) examined the knowledge management process in the Olympic Winter Games and in national (Ontario Summer Games and Canada Games) and international (Commonwealth Games and Pan American Games) multi-sport events. Schenk et al. suggested the following generic knowledge management process from Heisig for sports events: knowledge identification, acquisition, storage, creation, application, and transfer. But, they added learning and internal and external knowledge tailoring as part of this process, arguing the different hosting contexts/locations between editions of an event meant an adaptation could be required for knowledge to be useful once received.

Although this framework provides a valuable starting point to explore knowledge management and transfer within the YOG, we cannot assume the Schenk et al. (2015) model directly applies to the YOG context, not only due to the differing host country but also due to the nature of the YOG, in that it is a much newer event and one geared to younger athletes. Looking at Parent et al.'s (2015) study, there were differences in stakeholder salience and institutional context between the YOG and the Olympic Games. Though they did not compare the Olympic Games and YOG, specifically, Naraine et al. (in press) found stakeholder networks to differ between major/international and minor/national events. As such, we argue these differences may also impact other areas, such as knowledge management and transfer.

In summary, we will use the democratic governance principles and the 6 knowledge management/transfer process aspects as the starting points to help answer our research questions. Moreover, as governance may be intra- or inter-organisational, we consider internal as well as stakeholder-related governance aspects, thereby gathering data not 
Parent et al.

only from the Lillehammer 2016 Youth Olympic Games Organising Committee (LYOGOC) but also its key stakeholders or partners. As well, we will contrast the YOG governance findings with those of the Olympic Games context to draw out potential contextual particularities regarding sport event governance.

\section{Methodology}

We conducted a descriptive case study (Yin, 2013) of the Lillehammer 2016 Winter Youth Olympic Games (hereafter Lillehammer 2016) built by means of semi-structured interviews supported by documents. Below, we provide an overview of the research context, followed by our data collection and analysis techniques.

\subsection{Research Context}

Lillehammer 2016 took place between $12^{\text {th }}$ to $21^{\text {st }}$ February 2016 and had venues in Lillehammer, Hamar, Gjovik, Øyer and Oslo. Due to the distance between the different sport venues, two Olympic Villages and a hotel near Oslo were used to accommodate the 1,100 athletes aged 15 to 18 years old. Some venues from the Lillehammer 1994 Olympic Winter Games were reused in order to decrease costs. LYOGOC was established in 2012, with the Ministry of Culture (51\%), Lillehammer municipality (24.5\%), and the Norwegian Confederation of Sports and Olympic and Paralympic Committee (NIF) (24.5\%) as the event's owners. Four people were hired in August 2012, and the LYOGOC grew slowly, peaking at 130 paid staff during the Games.

An ongoing project for the Norwegian government has been to increase the focus on youth, through a 'youth promotion' (Ungdomsløftet in Norwegian) campaign designed to increase the promotion and recruitment of more young athletes, leaders and coaches (NIF, 2013). This also affected the hosting of Lillehammer 2016, as it was seen as a 'milestone for NIF's work with Youth Promotion in Norwegian sports. The Commission [NIF] believes this event gives Norwegian sports a unique opportunity to work purposefully to develop tomorrow's young athletes, coaches, leaders and volunteers' (Tvedt et al., 2013, p. 112).

\subsection{Data Collection}

Semi-structured interviews with LYOGOC members as well as key stakeholders constituted our primary data source. Documents supported and were included as part of the data analysis process.

We interviewed 13 individuals through purposeful sampling: 9 LYOGOC members and 4 key partner representatives. LYOGOC members ranged from the CEO, CFO and $\mathrm{COO}$, to department heads and lower-level employees, whereas the partners represented included Lillehammer municipality, Oppland County, NIF, and the IOC. We stopped interviewing once saturation was reached, that is, when no new and significant information was gleaned from the interviews.

Consent for the interview and its recording, as well as the confidentiality provision (no names noted, only organizations, with generic titles to be used during the reporting) 
Governance and knowledge management and transfer: The case of the Lillehammer 2016 Winter Youth Olympic Games

was obtained orally at the start of the interview, in accordance with our universities' ethics certificates.

The interview guide was developed using the governance and knowledge management/transfer literature noted above. First, we asked questions regarding governance: responsibilities, internal accountability, governance structures, performance, stakeholder participation in decision-making, and transparency (see Parent, 2016b). We then focusd on external accountability, followed by exploring the various aspects of Schenk et al.’s (2015) knowledge management process. Interviews lasted 43 minutes on average and were transcribed verbatim.

We complemented the interview data with documents provided to us by the interviewees. This included the Lillehammer 2016 bid documents, a 2012 progress report from LYOGOC to the IOC, and LYOGOC's Games Foundation Plan (its strategic document). In total, 174 document pages were added to the dataset.

Finally, we attended the event in February 2016 as observers, as well as to attend the $7^{\text {th }}$ International Sport Business Symposium during which an IOC member, an IOC staff representative, and a LYOGOC representative gave keynote presentations and answered questions. We also examined the event's website. These secondary sources served to corroborate our interview and document analysis.

\subsection{Data Analysis}

Data were inputted into the NVivo 11 Plus program for analysis. Deductive and inductive coding followed. Deductive codes included the democratic governance aspects noted by Parent (2016b), the knowledge management aspects from Schenk et al. (2015), and the stakeholder groups identified by Parent (2008). Inductive, in vivo coding also occurred for emerging codes, such as knowledge 'timing' and 'event logic.' Codes were then grouped into categories. We undertook axial coding to identify recurring patterns and themes in the data. These included, for instance, the importance of knowledge transfer timing (when it occurs) and the link between knowledge management/transfer obligations and the initial bid planning, as well as being linked to accountability and performance aspects of democratic governance. These were then grouped into higher order themes (cf. Corley and Gioia, 2004), which constitute our results detailed in the next section: governance aspects, knowledge management/transfer aspects, and linkages between governance and knowledge management/transfer.

In order to support our emerging findings, we ran NVivo word frequency queries for: governance overall as well as accountability specifically, knowledge management-related codes overall as well as for knowledge timing specifically (an emerging finding), and event management related codes. Each query's settings were kept at the default except the (word) groupings, which we set at 'With stemmed words' to avoid redundancies (e.g., responsible and responsibility were grouped together). As well, we ran NVivo matrix coding queries for event management codes with governance codes, event management codes with knowledge management codes, and governance codes with knowledge management codes. Outputs were automatically colour-shaded by NVivo for cooccurrence frequency of coding for ease of reading. Finally, we sent a draft of this paper to participants for feedback to increase the trustworthiness of the findings. 
Parent et al.

\section{Results}

We present our findings grouped by higher-order theme.

\subsection{Governance Aspects}

We found evidence of performance, accountability, transparency and participation in participants' governance explanations. Performance related mainly to the end-product, the Games, but also to strategic planning, objectives, efficiency and economy (cost considerations), similar to Parent (2016b). It was clear from the interviews there was broad stakeholder satisfaction with the organisation of the YOG although, as discussed below, there was some tension arising from the differences in organisational culture between the IOC and LYOGOC. Nevertheless, according to one IOC representative, 'honestly, for the final result, the value-added to the project that the Norwegians were able to bring tells me the Lillehammer Youth Olympic Games were the best.' A similarly positive assessment of the YOG came from the Lillehammer municipality though articulated in terms of knowledge acquisition ('the positive factor for us have been internal knowledge transfer within the organisation') and city/region branding ('to host an event like this boosts the identity as a place that hosts big events... Our aim is to become the premier winter destination in Northern Europe'). The NIF representative supported others' positive views:

"The evaluation is ongoing, but I think it went way over expectations, and many of the things that I worried about originally were a success. I think the voluntary approach was very good, it was a pride among the volunteers there to show that this was important to them, but also for the event. I know that some were surprised that so many people came... What remains to be seen is...how it will affect Norwegian sport in the future... but I am convinced that some of those who were young volunteers or young executives will be useful in their local communities."

With regard to internal accountability, the relationship was hierarchical in nature (cf. Parent, 2016b), through one's superiors, as noted in the following quotation:

"Formally speaking I'm only, in a way, accountable to the board... The board can demand things from me. And formally speaking again, the advisory board can advise and there are a lot of stakeholders who are involved can advise the board of directors, but not demand... It's the three owners who can really demand.” (LYOGOC representative)

However, within LYOGOC, orthodox hierarchical accountability was leavened by Norwegian cultural preference for organisational democracy. As one LYOGOC staff member commented about organizational decision-making, 'it's a bit too much discussion going on, everyone is allowed to say [something]... I think it may be a little bit more difficult to make a decision.' Though the advisory board (a body of 30 stakeholder representatives) noted in the preceding quotation is a departure from other sport event structures (cf. Parent and Smith-Swan, 2013), it did not change hierarchical accountability.

LYOGOC external accountability was mainly geared to the IOC, as the rights holder, and to the key partners, the host governments and NIF. As one LYOGOC representative commented 'Oh, it's three letters. It's I-O-C.' However, the formal hierarchical straightline accountability to the IOC was complemented by an extensive pattern of horizontal 
Governance and knowledge management and transfer: The case of the Lillehammer 2016 Winter Youth Olympic Games

accountability exercised by organisations intending or hoping to further their own objectives through involvement in the YOG, including: the five local municipalities (with concerns such as regional promotion and economic development through winter sport tourism); NIF (already an 'owner' of YOG but still concerned about delivering its national youth campaign via YOG); international federations (some of which used YOG to experiment with new sports); local sports clubs (seeking volunteer development opportunities); national television media (seeking coverage exclusivity); and sponsors (such as Omega, seeking increased public profile through YOG). For most of these stakeholders, there was the strong expectation they would be given an account by LYOGOC, and an equally clear understanding on the part of LYOGOC that they had a duty to account for decisions affecting these organisational interests.

The accountability relationship between LYOGOC (and other Olympic organising committees) and the IOC is distinctive. The IOC's project tracking structure relates to both performance and accountability. As the following LYOGOC representative explained, it operates at different levels, which parallel the structure of the organising committee:

"The top level is the CoComm, [the] Coordination Commission... that's the highest steering group in the IOC system, [and] consists of a couple of IOC athletes, a couple are people nominated by the IOC. It's the CEO of Innsbruck 2012... and there's a former skeleton athlete and there are a couple of [other] people... And so then every nine months we had one and a half day project status presentations and discussions and also decisions.

And then [at the next level there is] the project review, also approximately every nine months, but between CoComms .... The project review is done, not with the CoComm IOC members, so to speak, but with the ... IOC administration. So the highest person there for me is the Games Director. And then the whole team from the administration.

And then there's the level below, there is the technical meetings. Technical meetings are more or less formal/informal meetings related or placed quite close in time to either CoComms or project reviews. Then we have the last CoComm and we had as much as 47 technical meetings ... problem solving, discussing and developing the concepts.

And then the level below there is the FA [functional area], FA informal discussions between technical meetings. It's one step between those two. It's the monthly calls. We have monthly calls with the management level of the IOC administration.”

The third key element of governance related to transparency openness and communication. The high level of external transparency was usually explained as a requirement of the legal incorporation of the organization and the Norwegian transparency laws it therefore had to follow. As Parent (2016b) noted, there was a chain of command to follow for reporting, demonstrating the blurring of lines between internal transparency and internal accountability. However, the legal obligations were reinforced by Norway's public sector culture, which prioritises openness and access to decisionmaking processes, illustrated by the extensive access the media and academic researchers were given to LYOGOC personnel and documents. As one LYOGOC representative commented, 'we need to have an openness that a business does not need to have... This is normal in Norway, but the IOC is not too used to this'. 
Parent et al.

Regarding participation, the bid document gave clear priority to wide involvement: It is our goal to develop an event that is led by youth, where youth take active part in the planning, staging and follow-up of the YOG 2016. In the process leading up to our bid for the YOG 2012, we established cooperative agreements with a wide range of youth organizations from areas outside of sports. We will continue this cooperation in relation to the planning and staging of YOG 2016. (Bid book volume 1, p. 6)

The commitment made at the bid stage was fulfilled by LYOGOC, supported by its advisory board and assisted by numerous youth, sport, volunteer, welfare and education partners so LYOGOC could offer a wide range of events planned and delivered by youth for youth. This engagement goal seemed pervasive, from the relative youth of the organizers, to the use of youth for their branding and planning, as noted in their Games Foundation Plan, and as also seen in the use of an advisory board with substantial youth representation. Similar to Parent (2016b), stakeholder (active) engagement was key, and was planned, for example through the Torch Relay, the young enthusiasts'/devotee program (unge ildsjeler) and the young leaders' program. LYOGOC also used social media (e.g., website, Twitter, Facebook, and Instagram) to increase national and international engagement.

One LYOGOC staff member who had worked at a number of previous Olympic Games (including the Sochi Olympic Winter Games and the Innsbruck YOG) commented on the distinctiveness of LYOGOC's management style: 'It's very liberal here. Management level is very flat. So decisions sometimes can be a little bit harder because everybody has a say, which is democracy.' LYOGOC's democracy and openness was balanced by a clear strategic vision encapsulated in the five strategic objectives it identified and a willingness to defend its vision of the Games. As another LYOGOC representative commented 'I find it quite comical that our values are "raw and humble." Raw yes - but humble? Not at all! They are like "they cannot tell us how to host ski races.' LYOGOC's culture willingly accepted accountability as an obligation to share information (knowledge). However, it did so with a clear view of the type of event it wanted to present.

\subsubsection{Event logic}

One emerging theme related to the event's logic, defined here as: the attitude or approach used to manage and coordinate the activities related to, and stakeholders associated with, the planning and hosting of a given event. The IOC acknowledged the YOG are not only a new event, but are also (and are intended to be) a different type of event to the Olympic Games. Though requiring careful project management, the strategy adopted is distinct, emphasizing a lower use of formal documents in favour, in the words of an IOC representative, of 'a common construction logic, of co-construction of the event.' He added:

"We're more trying to say, we don't know what is the proper way of doing things in Norway... So we'll rather explain to you where we would like to go, the why we do all this, what we'd like as a final result... That way, we leave the organising committee's hands free and we work together to find the best solutions, and we try to be the most flexible possible.” (IOC representative) 
Governance and knowledge management and transfer: The case of the Lillehammer 2016 Winter Youth Olympic Games

The IOC representative noted four possible event logics (see Table 1 for quotations from the representative):

- Prescriptive: When a solution has worked in the past and is not context dependent. Here, the event rights holder takes responsibility for the outcome.

- Pedagogical: When a solution is context dependent and beyond the event rights holder's abilities. The event rights holder asks the appropriate questions so the organising committee can find the 'right' solution.

- Counselling: When an organising committee or file is working well but there is a need for encouragement and to help move the process forward.

- Delegation: When an organising committee or file is working well and an intervention from the event rights holder would actually slow the process down or would not provide any added value.

As the above quotation from the IOC representative highlighted, in the case of Lillehammer 2016, the event logic was not prescriptive, but more pedagogical.

\section{[Insert Table 1 about here]}

A second key governance theme related to the importance of understanding the event management process and then challenging 'the way of doing things,' while remaining flexible. As a LYOGOC representative noted, it is important to challenge ways of doing to increase effectiveness and efficiency (i.e., performance):

"The IOC has given us a manual, and we have challenged almost all aspects of it, which is good. YOG is like a newborn baby, and they [the IOC] are open for changes, but that process can be very tough. You need to have very strong arguments why [to suggest a] better way to do it, or less complicated [way].”

The IOC representative acknowledged and supported this pedagogical and negotiation approach, as such challenges demonstrated the organising committee's understanding of what needed to be done and why:

"If the organising committee doesn't challenge us ... [t]here's a problem... When we present our solution and the organising committee says yes, that's really good, we'll do it like that, we say oh, now, there's a problem. Either they didn't understand, either they don't want to tell us, that culturally they don't have the habit of doing otherwise, or they have another opinion, or they haven't appropriated the solution...

So, that means that when an organising committee finds what we propose to be good, it's that maybe... we may not yet have a sufficiently close relationship for them to feel they can tell us they want to do things differently or, what we propose to them doesn't interest them and they haven't examined it closely enough.

We say as long as they haven't told us they want to do things differently, we haven't...yet built a good relationship with them.” 
Parent et al.

\subsubsection{Context \& Culture}

The event logic and being able (or willing) to challenge, as well as the overall event governance process, are dependent on the organizing committee's context and culture, as alluded to above. The IOC representative explained the contextual and cultural aspects as follows:

"most of the problems are contextual. Most problems are also linked to elements on which we rarely have control. And, in fact, when we put the solutions, they piled on top of each other. And, sometimes, we transmitted solutions to problems that weren't posed. And organising committees, instead of seeing it as assistance in providing solutions in case they found the problem, they thought it became new obligations.

We [the IOC] underestimated...the cultural differences between Northern Europe and, we'll say Central Europe for Switzerland, or in certain cases the South ... we underestimated the cultural differences... There were practically as many differences working with the Norwegians as with the Chinese. It was really, really, really, really different in their way of working, in their way of making decisions, in identifying who has authority in relation to hierarchical authority and functional authority, and their way of providing comments or receiving comments."

The distinctiveness of Norwegian organisational culture was confirmed by a number of other interviewees, some of whom had worked at earlier Olympic events elsewhere. One commented, 'In [my home country,] I was super integrated in the society. The social codes are very interesting here, and people expect me to be Norwegian.' Another commented, 'here [Norway] we have to write a lot of our own policies and procedures.' The cultural differences were echoed by some Norwegian LYOGOC representatives. One noted, 'I think some people felt the IOC was a very different culture.' Another said, 'at first it was kind of frustrating...the Scandinavian people, we're used to being told this is the goal, get there.' The net effect of the cultural differences between the host nation and the IOC was that, as one LYOGOC representative commented, 'the host nation has to compromise a little bit, because this is an IOC event. But the IOC has to compromise, because this is being held in a host nation, and there are certain cultures that cannot be aligned with everyone.'

The differences in context and culture can also hold within the host country, as demonstrated by the Oppland County representative: 'Lillehammer Municipality chose their own way to do it... They had one person working on this longer than us... They chose a different approach and did not work as close with the schools as we did.'

One aspect perceived to have helped LYOGOC be more independent in its approach was the physical/geographic distance between it and the IOC. This aspect was noted by a LYOGOC representative and an IOC representative during the $7^{\text {th }}$ International Sport Business Symposium held in Lillehammer during the Games, and also mentioned by the NIF representative during his interview:

"They [the organising committees] must be themselves. I am quite happy the IOC does not have its headquarters in Lillehammer, I think distance and responsibility of an OC [organizing committee] is important for the result. The IOC have their daily work, and they should stay away from the event itself. Of course, they will control and help, but they must leave the 
Governance and knowledge management and transfer: The case of the Lillehammer 2016 Winter Youth Olympic Games

OC do its task. I think the hardest thing for Lausanne [the host of YOG 2020] will be creating a distance to the IOC; it is necessary for the execution that there is distance.

\subsection{Knowledge Management/Transfer}

Data analysis revealed the basic knowledge management/transfer process described by Schenk et al. (2015) also applied in the case of Lillehammer 2016. We found evidence of knowledge identification, acquisition, application, creation, storage, learning, tailoring and transfer. However, our analysis pointed to the importance of knowledge transfer timing. It also pointed to differences between, not only explicit and tacit forms of knowledge, but also strategic versus operational forms. These two key findings are presented below.

\subsubsection{Knowledge timing}

OCOGs have six and half to seven years to plan for the Olympic Games. Two key aspects of the IOC's Olympic Games Knowledge Management (OGKM) program constitute observing the previous host and the city-to-city debrief, from the previous host to the next host, which occurs about six months post-Games. At this time, OCOGs have been in existence for three years, with another three and a half to four years left, and the senior staff members have been hired. As such, OCOGs are nearing the end of their planning mode or transitioning into implementation mode at this point.

In contrast, YOG organising committees have about five years to plan for the event, and are constituted about six months prior to the hosting of the previous edition, where they are present as observers. Likewise, the city-to-city debrief takes place less than one year from the organising committee's inception. At this time, the leader may (or may not) have been officially hired, and it is unlikely other staff members have. As such, YOG organising committees are in the beginning of the planning mode. The IOC representative highlighted this timing issue:

"There's a huge factor that has to be considered. It's that the Lillehammer Youth Olympic Games took place really soon after the election of Lausanne [2020 Games]. Lausanne was elected at the IOC session in Kuala Lumpur, which took place in summer 2015, and so not even six months later, we have the Lillehammer Youth Olympic Games. So the Lausanne people, the executive director wasn't even officially hired yet. So, the knowledge transfer, it's really, really, really difficult to do a technical knowledge transfer, focused, detailed, with the Lillehammer people or just after Lillehammer, whereas on Lausanne's side people aren't recruited yet."

This timing makes knowledge transfer more difficult for the YOG than the Olympic Games. Even if a senior staff member is hired, they may not be ready to receive knowledge, especially not technical knowledge, as this LYOGOC representative noted: "But the organising committee's so small. I mean, here, there are only three people... I think my colleagues wanted to share [knowledge], but people were not ready to receive it, because they were not the right people 


\section{Parent et al.}

who would need this knowledge."

Thus, we find lifecycle timing to be an important, but previously neglected, consideration in the sport event knowledge management/transfer process. At the same time, our data analysis revealed the knowledge transfer process is not only done post-Games, with the Games observation or city-to-city debrief. It occurs continually, throughout the organising committee's lifecycle, as the IOC representative noted: 'All the time, every day, every minute. In fact, it's a permanent process. It doesn't happen at one particular moment. It has to be done all along organizing committees’ lifecycles.'

\subsubsection{Types of knowledge}

The above points on timing and continual knowledge transfer relate to the event committee's lifecycle, as the IOC representative's quotation noted. Our data analysis revealed there is a knowledge transfer process occurring in parallel with the organising committee's lifecycle. During the planning mode - the first half of the organising committee's life - strategic-level knowledge is more important. Only when the organising committee is in its implementation mode, thinking in more concrete terms, does it require operational-level or technical knowledge. As such, we contribute to the literature by noting the explicit-tacit knowledge type distinction exists but, for temporary organisations, such as a sport event organising committee, there are distinctions to be made between strategic-level and operational/technical-level knowledge. Strategic-level knowledge, which is the primary concern during the planning mode, dominates discussions at the city-to-city debriefs and at meetings of national-level organisations. The following extract from the 2012 Lillehammer report to the IOC Session illustrates the strategic focus:

"On the 20th of June 2012 the first City to City debrief was held in Lillehammer. Both the IOC and the I[nnsbruck]YOGOC was present. LYOGOC and the NOC [NIF] invited a wide array of local, regional and national YOG 2016 stakeholders to this meeting. For LYOGOC, the City to City debrief represents an important occasion for us to make sure that our present and future project partners are given first-hand information about the complexities and opportunities connected to the planning and staging of the Youth Olympic Games.”

This early strategic focus was confirmed by the IOC representative, who said of the cityto-city meeting, 'at an executive level, we're more that it be the people from the city who come present to the others, the people of the Lillehammer municipality who will come present to the people of the Lausanne municipality, the Norwegian Olympic Committee who will present to the Swiss Olympic Committee, but at a strategic level.'

As Games-time approaches, the focus shifts to operational knowledge. As the IOC representative noted,

"After [the city-to-city debrief], we'll do the more specific knowledge transfer, either with the IOC staff that will have obtained elements from Lillehammer, who will transmit them to Lausanne, or either by having someone from Lillehammer come when necessary, but maybe in a year and a half or two. Two years after. And after, we always have documents available."

This technical knowledge view was endorsed by a LYOGOC representative:

"It can be big things, you can talk about arrivals and departure, and then 
Governance and knowledge management and transfer: The case of the Lillehammer 2016 Winter Youth Olympic Games

you calculate how much luggage does an average traveler bring, sport equipment. If you have not done this before and do your estimations on a normal traveler, one suitcase and a pair of skis, it will not work, that is an example, a very practical example. Then, the IOC will tell us how much we need to calculate per athlete, and then we can cover the needs.”

\subsection{Governance \& knowledge management/transfer}

As noted above, we found a relationship between the event's lifecycle and knowledge transfer timing and type of knowledge. First, the bid committee acquires and uses explicit (documents) and tacit (expertise, experience, for example of 'Games Gypsies,' those who have worked at previous Olympic events) knowledge of the bid, as the Lillehammer 2016 Bid document volume 1 noted:

"This bid application has been developed after careful study, based on the requirements of the IOC, the physical and logistic attributions of the Lillehammer region, as well as the background, expertise and contributions of a wide range of personnel and organizations that will actively support the YOG 2016 in Lillehammer."

If the bid committee is successful in winning the right to host the event, the newlyformed organising committee will obtain strategic-level, tacit (e.g., meetings between the heads of the events, past-Games experience/expertise, and training) and explicit knowledge, as the following quotations highlight:

"The need for volunteers in the YOG 2016 will be covered by youth, who in the planning phase will have the opportunity to qualify for positions and assignments, mixed with experienced staff from other major sport events. We will ensure that the youth's diverse and unique talents have the chance to develop and demonstrate their skills during the planning and staging of the event.” (Lillehammer $2016 \mathrm{Bid}$ document volume 1)

"I think the Lausanne executive director talked a lot with [Lillehammer 2016 CEO]. That happened naturally. There has been some knowledge transfer. It's this informal knowledge transfer that works the best.” (IOC Representative)

Eventually, as staff members are hired and the organising committee moves into the implementation mode, it focuses on operational-level knowledge, again both tacit and explicit, as described earlier.

However, the relationship between knowledge management/transfer and governance aspects goes further than the issue of timing and type of knowledge. Examining the outputs of NVivo's matrix coding queries, we found linkages, co-occurrences, between knowledge management/transfer-related codes and governance-related codes, especially with accountability and performance.

Accountability was linked most strongly (co-occurred more frequently; i.e., at 5-9 out of 9) with: knowledge transfer, knowledge tools (i.e., communication, meetings and reports), and explicit knowledge. It also linked moderately (co-occurrence of 3) with knowledge acquisition, knowledge tools (i.e., liaison), and the operational and tacit types 
Parent et al.

of knowledge. Hierarchical (internal) accountability linked moderately (co-occurrence of 4) with knowledge transfer.

Performance was linked most strongly (co-occurrences of 5-9) with knowledge transfer, learning, and both explicit and tacit types of knowledge. It also linked moderately (co-occurrence of 3) with knowledge tools (i.e., communication).

Participation and transparency had weak (i.e. co-occurrence of 1) to no cooccurrences with knowledge management-related codes.

Authority, an emerging code denoting a hierarchical (intra-organizational) form of power, linked most strongly (co-occurrence of 6) with knowledge tools (i.e., communication), and moderately (co-occurrences of 3-4) with knowledge transfer knowledge tools (i.e., liaison), and both explicit and tacit forms of knowledge.

Finally, the overall event's governance - that is, not specific to an aspect of democratic governance - linked most strongly (co-occurrence of 5) with knowledge tools (i.e., communication) and moderately (co-occurrence of 3 ) with knowledge tools (i.e., people and expertise) and explicit knowledge.

So, knowledge transfer processes are primarily affected by: accountability (all forms), authority, and performance aspects of governance. Knowledge tools are more often linked to accountability, than any other aspect of democratic governance. However, communication, a type of knowledge tool, is linked to accountability, authority, performance and overall governance. Explicit knowledge is linked to a higher degree and more broadly/generally to governance aspects than tacit knowledge.

\section{Discussion and conclusions}

This paper's purpose was to examine the relationship between knowledge management/transfer processes and good governance practices. Our specific research questions were: 1 ) what is the relationship between good governance principles and the knowledge management/transfer process; and 2) to what extent does knowledge management/transfer in the YOG compare with that of the Olympic Games process.

In relation to the first research question, the elasticity of the governance concept was noted in the earlier discussion, as was the tendency of governance arrangements analyses to be combined with normative concerns, providing prescriptions for 'good governance.' Following our findings, and the literature, governance has two interrelated elements - one focused on structures and the other on culture. As a recent analysis of governance structures in 35 international sport federations confirms, it is possible to meet current expectations of good governance in a structural sense, but not in a cultural sense (Geeraert 2015). In Geeraert's analysis, both FIFA and the IAAF (International Association of Athletics Federations) ranked in the top quartile for structural features, but have recently been mired in allegations of serious corruption. In relation to the YOG, the IOC was prescriptive in terms of governance and knowledge management structures which facilitated tight accountability from the strategic to the operational levels. The prescriptive nature of the IOC's structural requirements was, in part at least, an acknowledgement of its inability to control domestic organisational and political culture, as well as of the YOG being a relatively new event and thus, not having a significant base on which to develop solutions to specific problems. However, this lack of control over domestic organisational culture did not prove problematic in Lillehammer, as the domestic culture was one of openness (admittedly reinforced by domestic law) and 


\section{Governance and knowledge management and transfer: The case of the Lillehammer 2016 Winter Youth Olympic Games}

consultative/democratic decision-making. If the IOC had a concern it was with the extent of openness and internal democracy. LYOGOC's analysis illustrated a realistic balance between organisational effectiveness and efficiency (i.e., performance) on the one hand and the sometimes idealised expectations of good governance.

As mentioned earlier, two forms of accountability were operating in Lillehammer traditional hierarchical and horizontal. Hierarchical straight-line accountability was most evident in the relationship between the IOC and LYOGOC, reflected in the strict regime of meetings and reporting protocols. The accountability relationship with the other two co-owners (the Ministry of Culture and NIF) skewed toward NIF, despite the Ministry being the majority shareholder. This is perhaps due to NIF leadership role in the Norwegian sport system and its youth promotion campaign. Although NIF had a formal hierarchical relationship with LYOGOC, it acted more as a participant in the horizontal accountability process, situating itself as one of many stakeholders seeing LYOGOC as much as a partner as an agent. In this regard, the sense in which LYOGOC was held to account by NIF and other organisations (such as the municipalities, local clubs, NGBs and media) was notional at best, with most seeing LYOGOC as a co-creator of their preferred outcomes. However, rather than this pattern of relationships indicating an absence of an accountability process, it is more likely that it simply reflects a society/context where trust and confidence in partner organisations is high.

In regards to the relationship between good governance principles and the knowledge management/transfer process, one concern expressed by some sceptics in what could be termed the 'good governance movement' is that good governance becomes an end in itself rather than a means to an end. As Grindle (2016) argued, there is a serious risk in management discussions that an assumption is made of a causal relationship between good governance and the achievement of organisational objectives and, more significantly, that organisational objectives cannot be achieved unless good governance practices prevail. What is clear from this research is that, while good governance might facilitate the management and transfer of knowledge, it does not ensure organisational effectiveness (performance). Our results indicated knowledge management/transfer processes appear more strongly linked to accountability than performance. Moreover, the most important attribute of good governance seems to be the cultural context within which governance structures and practices function. A culture of openness and democratic decision-making contributes significantly to the effective exploitation of knowledge. What is evident from our study is that, while the provisions of reports and city-to-city debriefs were important, of greater importance was the on-going willingness of key managers of one YOG to maintain contact and act as informal advisors to the managers of the next YOG, as well as the willingness of key staff to live a peripatetic lifestyle and move from one Olympic event to the next, bringing with them their accumulated formal and tacit knowledge. In summary, people were a more important vehicle for knowledge transfer than paper. This supports Parent et al's (2014b) and Schenk et al's (2015) findings regarding the importance of people.

With regard to our second research question - the comparison of the knowledge transfer process with that found at the Olympic Games - the most significant finding concerns timing, the problematic consequences of the short overlap between one YOG and the next, which reduces the opportunity for the incoming organizing committee to observe and learn from the current organizing committee. A second difference arises 
Parent et al.

from the concern by the IOC that the YOG should be different in terms not only of content, but also organisation and management from the Olympic Games. The interview data from the IOC representative indicated a conflict between the IOC's understandable desire to ensure the successful delivery of the product and the concern to ensure the YOG was an event which would attract a new, younger audience and hopefully reinvigorate the Olympic Movement. To this end, the IOC is currently reviewing all aspects of the YOG from goals to processes - to determine the event's fate.

\subsection{Contributions and implications}

We contribute to the event governance literature by highlighting the importance of:

- Hierarchical and horizontal accountability;

- $\quad$ Planned, active stakeholder engagement;

- $\quad$ Event logic and the relationship between event rights holder and organizing committee;

- $\quad$ Context; and

- Societal and organisational culture.

We also contribute to the sport event knowledge management/transfer literature by highlighting the importance of knowledge transfer timing and strategic versus operational knowledge. We also contribute to the sport event management literature by demonstrating the interrelationship between good governance principles and knowledge management/transfer processes, which is another step in the development of a sport event conceptual map (cf. Chalip, 2006; Parent, 2016b).

From a practitioner standpoint, our study demonstrates the need for event rights holders to consider potential host locations, not only from technical/ability and audiencegrowth perspectives, but also from the local context and culture, as these will affect governance and knowledge management/transfer processes, but also, and perhaps more importantly, the relationship between the rights holder and the organizing committee.

\subsection{Limitations and future directions}

As with all studies, ours had limitations. First, though we reached data saturation with our interviews and supplemented the information with archival material, we did not interview representatives of all stakeholder groups, only those key partners in the event's governance. With the information in the present paper, it would be worth surveying all levels of the organizing committee - as we know there can be differences (see Parent, 2008) - as well as representatives of all stakeholder groups to determine the extent of accountability and knowledge management/transfer activities. Second, evaluating governance and knowledge management/transfer process outcomes was beyond the scope of this paper. Thus, it would be worthwhile to continue this study longitudinally by interviewing the IOC and future hosts (Buenos Aires 2018 and Lausanne 2020) to determine what Lillehammer 2016 governance and knowledge management learnings were implemented and what the outcomes of this knowledge transfer were. Finally, we used a democratic governance approach, which fit with Norway's democratic culture. As noted earlier, there are many definitions of and approaches to 'good governance.' We therefore suggest researchers could use other approaches to examine particular aspects in 
Governance and knowledge management and transfer: The case of the Lillehammer 2016 Winter Youth Olympic Games

greater depth, such as using collaborative governance (see Shilbury and Ferkins, 2015) to examine the event partnerships more closely.

\section{References}

Bevir M. (2010) Democratic Governance, Princeton, NJ: Princeton University Press.

Callahan K. (2007) Elements of Effective Governance: Measurement, Accountability and Participation, New York: CRC Press.

Chalip L. (2006) Toward a distinctive sport management discipline. Journal of Sport Management 20, 1-21.

Chappelet J-L and Kübler-Mabbott B. (2008) The International Olympic Committee and the Olympic system: The governance of world sport, Oxon, England: Routledge.

Corley KG and Gioia DA. (2004) Identity ambiguity and change in the wake of a corporate spin-off. Administrative Science Quarterly 49: 173-208.

De Leon L. (2003) On acting responsibly in a disorderly world: Individual ethics and administrative responsibility, In Peters, B.G. \& Pierre, Handbook of Public Administration. London: Sage Publications Ltd, 351-364.

Digel H. (2008) The Risks of the Youth Olympic Games. New Studies in Athletics 23: 53-58.

Ferkins L and Shilbury D. (2015a) Board strategic balance: An emerging sport governance theory. Sport Management Review 18: 489-500.

Ferkins L and Shilbury D. (2015b) The Stakeholder Dilemma in Sport Governance: Toward the Notion of "Stakeowner". Journal of Sport Management 29: 93-108.

Geeraert, A. (2015) Sports governance observer 2015, Cpoenhagen: PLay the Game.

Girginov V. (2012) Governance of the London 2012 Olympic Games legacy. International Review for the Sociology of Sport 47: 543-558.

Grindle, M. S. (2016) Good governance RIP: A critique and an alternative. Governance doi:10.1111/gove.12223

Halbwirth S and Toohey K. (2001) The Olympic Games and knowledge management: A case study of the Sydney Organising Committee of the Olympic Games. European Sport Management Quarterly 1: 91-111.

Hanstad DV, Parent MM and Houlihan B. (2014) The Youth Olympic Games. London: Routledge.

Hanstad DV, Parent MM and Kristiansen E. (2013) The Youth Olympic Games: the best of the Olympics or a poor copy? European Sport Management Quarterly 13: 315-338.

Heisig P. (2009) Harmonisation of knowledge management - comparing $160 \mathrm{KM}$ frameworks around the globe. Journal of Knowledge Management 13: 4-31.

Hoye R. (In press) Sport governance. In: Hoye R and Parent MM (eds) The SAGE handbook of sport management. London: SAGE Publications, Inc.

Jasimuddin SM. (2012) Knowledge management: An interdisciplinary perspective, New Jersey, NY: World Scientific Publishing Co Pte Ltd.

Krieger J. (2013) Fastest, highest, youngest? Analysing the athlete's experience of the Singapore Youth Olympic Games. International Review for the Sociology of Sport 48: 706-719. 
Parent et al.

Kristiansen E. (2013) Competing for culture: Young Olympians' narratives from the first winter Youth Olympic Games. International Journal of Sport and Exercise Psychology in press: 1-14.

Loland S. (2014) The Youth Olympic Games and the Olympic ideal. In: Hanstad DV, Parent MM and Houlihan B (eds) The Youth Olympic Games. London: Routledge, 19-33.

Mintzberg H. (1979) The structuring of organizations, Englewood Cliffs, NJ: Prentice Hall.Newman, J. (2004) Constructing accountability: Network governance and managerial agency Public Policy and Administration 19: 17-33.NIF. (2013) Arsrapport 2013 [Annual report 2013]. Oslo, Norway: Norwegian Olympic, Paralympic Committee and Confederation of Sports. Retrieved from http://www.idrett.no/omnif/idrettsstyret/Documents/NIF\%20Årsrapport\%20201 3_LR.pdf

Naraine ML, Schenk J, and Parent MM (in press) Coordination in international and domestic sports events: Examining stakeholder network governance. Journal of Sport Management

O’Loughlin, M.G. (1990), 'What is bureaucratic accountability and how can we measure it?’. Administration and Society, 22: 275-302.

Parent MM. (2008) Evolution and Issue Patterns for Major-Sport-Event Organizing Committees and Their Stakeholders. Journal of Sport Management 22: 135-164.

Parent MM. (2016a) The governance of the Olympic Games in Canada. Sport in Society 19: 796-816.

Parent MM. (2016b) Stakeholder perceptions on the democratic governance of major sports events. Sport Management Review 19: 402-416.

Parent MM, Kristiansen E and MacIntosh EW. (2014a) Athletes' Experiences at the Youth Olympic Games: Perceptions, Stressors, and Discourse Paradox. Event Management 18: 303-324.

Parent MM, Kristiansen E, Skille EA, et al. (2015) The sustainability of the Youth Olympic Games: Stakeholder networks and institutional perspectives. International Review for the Sociology of Sport 50: 326-348.

Parent MM, MacDonald D and Goulet G. (2014b) The theory and practice of knowledge management and transfer: The case of the Olympic Games. Sport Management Review 17: 205-218.

Parent MM and Smith-Swan S. (2013) Managing Major Sports Events: Theory and Practice, London: Routledge.

Parry J. (2012) The Youth Olympic Games - some Ethical Issues. Sport, Ethics and Philosphy 6: 138-154.

Polanyi M. (1966) The Tacit Dimension, New York: Anchor Books.

Preuss, H., Siller, H., Zehrer, A., Schütte, N., and Stickdorn, M. 2010. Regionale ökonomische Auswirkungen der UEFA EURO 2008 für Österreich. Wiesbaden: Gabler.

Rhodes, R.A.W. (1997) Understanding governance, Milton Keynes: Open University Press.

Romzek, B. (1996), Enhancing accountability. In Perry, J. L. (ed.) Handbook of Public Administration ( $2^{\text {nd }}$ edition), San Francisco: Jossey-Bass, 97-114.

Schenk J, Parent MM, MacDonald D, et al. (2015) The evolution of knowledge management and transfer processes from domestic to international multi-sport events. European Sport Management Quarterly 15: 535-554. 
Governance and knowledge management and transfer: The case of the Lillehammer 2016 Winter Youth Olympic Games

Scott, C. (2000) Accountability in the regulatory state. Journal of Law and Society 27: 38-60.

Schnitzer, M., Bodner, B., Scheiber, S., Thöni, E., and Kopp, M. 2015. Konsumverhalten von Eventbesuchern der Olympischen Jugend-Winterspiele am Beispiel Innsbruck 2012. Sportwissenschaft doi: 10.1007/s12662-015-03859.

Shilbury D and Ferkins L. (2015) Exploring the Utility of Collaborative Governance in a National Sport Organization. Journal of Sport Management 29: 380-397.

Stewart, J. (1994) The rebuilding of public accountability. In Flynn, N. (ed.) Change in the civil service London: CIPFA reader, 75-79.

Theodoraki E. (2007) Olympic Event Organization, London: Butterworth-Heinemann.

Thomas, P.G. (1998), The changing nature of accountability. In Peters, B.G. \& Savoie, D. (eds.) Taking stock: Assessing public service reform, (Kingston: McGill University Press).

Thöni, E., and Philippovich, T. 2008. Sozio-ökonomische ex post Evaluierung der Winteruniversiade Innsbruck/Seefeld 2005. Wien: Kovac.

Tvedt T, Røste E, Smith M, Høgmo PM, Haugen K, and Rognlan LT. (2013) Den norske toppidrettsmodelen-norsk toppidrett fram mot 2022 [The Norwegian top sport model - Norwegian sport towards 2022]. The Norwegian Olympic and Paralympic Committee and Confederation of Sports (NIF). Retrieved from http://www.idrett.no/nyheter/Documents/Toppidrettsrapporten_2022.pdf

Van Kersbergen K. and van Waarden F. (2004) 'Governance' as a bridge between disciplines. European Journal of Political reearch 43: 143-171.

Winter SG. (1987) Knowledge and competence as strategic assets. In: Teece DJ (ed) The competitive challenge. Cambridge, MA: Ballinger, 159-184.

Wong D. (2011) The Youth Olympic Games: Past, Present and Future. International Journal of the History of Sport 28: 1831-1851.

Yin RK. (2013) Case Study Research: Design and Methods, Thousand Oaks, CA: SAGE Publications, Inc.

Zander U and Kogut B. (1995) Knowledge and the speed of the transfer of organizational capabilities. Organization Science 6: 76-92.

Table 1 Event logic examples

\begin{tabular}{ll}
\hline Event logic & Quotation Example \\
\hline Prescriptive & $\begin{array}{l}\text { We can, it's in project management...phases that we can be pretty } \\
\text { directive. In certain cases, we have to be at the IOC level. We can say, } \\
\text { well, on this topic, here's what you have to do. And then, clearly, we } \\
\text { can be very prescriptive and we take responsibility of the solution } \\
\text { because we say, okay, well, that's not contextual. That, we've already } \\
\text { done that, so we know that works. (IOC representative) }\end{array}$ \\
& $\begin{array}{l}\text { In certain instances, we're much more pedagogical. We try to not give } \\
\text { Pedagogical } \\
\text { the organising committee, to really give assistance, so that it can find } \\
\text { the right solution, because it's not the only who can find the right }\end{array}$ \\
\hline
\end{tabular}


Parent et al.

\begin{tabular}{l}
\hline $\begin{array}{l}\text { solution, because the right solution, it is fundamentally the one that } \\
\text { works in the country. And that, we don't know how to do. (IOC } \\
\text { representative) }\end{array}$ \\
$\begin{array}{l}\text { And in certain cases, the organising committee functions well. What } \\
\text { we have to give it is to encourage it, it's to help it move forward. We } \\
\text { interact with them. We're in more of a counselling type of logic. (IOC } \\
\text { representative) }\end{array}$ \\
$\begin{array}{l}\text { And in certain cases, on certain files, at certain moments, everything } \\
\text { goes well, it's progressing well. We, somewhere, if we intervene too } \\
\text { much, we're going to make them lose time. They'll be obliged to } \\
\text { inform us on what they're doing. And in fact, there's no value-added. } \\
\text { So there, we have to be able to be in a confidence logic, of delegation, } \\
\text { and we practically, we in an activity where we do only a little bit of } \\
\text { control. We come from time to time do some extraction on what's } \\
\text { happening. (IOC representative) }\end{array}$ \\
\hline
\end{tabular}

